\title{
Effects of Reticuloendotheliosis Virus and Marek's Disease Virus Infection and Co-infection on IFN-Gamma Production in SPF Chickens
}

\author{
Yu-shu ZHENG ${ }^{1)}$, Zhi-zhong CUI ${ }^{1}$, Pu ZHAO ${ }^{2)}$, Hong-mei LI $^{1)}$, Cui-yan LIU' ${ }^{1}$, Zhao-ju TIAN ${ }^{1)}$ and \\ Hong-kun $\mathrm{ZHAO}^{1) *}$ \\ ${ }^{1)}$ College of Veterinary Medicine, Shangdong Agricultural University, 61 Daizong Street, Taian, Shandong, 271018 and \\ ${ }^{2)}$ Department of Animal Science, Henan Institute of Science and Technology, Xinxiang, 453003, China
}

(Received 7 June 2006/Accepted 30 August 2006)

ABSTRACT. Two experiments were used to examine the potential role of IFN- $\gamma$ in chickens infected with reticuloendotheliosis virus (REV) and Marek's disease virus (MDV). First, chickens were infected with REV and/or MDV at 5 days of age and examined from 3 to 50 days post-infection (dpi). In REV+MDV co-infection chickens, IFN- $\gamma$ ELISA demonstrated a 3-fold increase at 7 dpi compared to the controls, while REV alone caused a 5-fold increase, the IFN- $\gamma$ levels peaked, and then gradually decreased. IFN- $\gamma$ levels significantly decreased in MDV infection at $3 \mathrm{dpi}$ and $15 \mathrm{dpi}$. Second, experiments were designed to determine the effects of different viruses and ConA on IFN- $\gamma$ production. For REV- or MDV- infected chickens, the IFN- $\gamma$ levels decreased slightly after adding ConA. This is the first report of IFN- $\gamma$ production in SPF chickens infected with REV and MDV measured by directly quantitative method.

KEY WORDS: IFN-gamma Marek's disease virus, reticuloendotheliosis virus.

Reticuloendotheliosis virus (REV) is an avian retrovirus and Marek's disease virus (MDV) is an alphaherpesvirus, both of them can result in tumors and immunosuppression $[10,11,15]$. Dual infection of REV with MDV is common in many countries and areas [3,4], yet the mechanism of REV- or MDV-induced immunosuppression has not been completely characterized [6]. There is a paucity of knowledge concerning the role of cytokines in reticuloendotheliosis or MD infection, pathogenesis and immunity. Cytokines have been implicated in the maintenance of MDV latency, especially IFN- $\alpha$ and a soluble latency-maintaining factor [2]. Some studies investigated the effects of virus infection on the expression of cytokines at the transcription level [13, 14]. Kaiser et al. [9] quantified the production of cytokine mRNAs by real-time quantitative reverse transcription-PCR (RT-PCR) in splenocytes during the course of MDV infection in resistant and susceptible chicken lines. Kaiser et al. [9] proposed that IL-6 and IL-18 could play a crucial role by driving immune responses that in resistant lines maintain MDV latency and in susceptible lines result in tumor formation. Markowski-Grimsrud and Schat [11] demonstrated that infection with REV (REV-CS strain) alone resulted in a 10 -fold increase in IFN- $\gamma$ mRNA levels in 9- to 10- or 30day-old birds.

The present study was to determine IFN- $\gamma$ at the protein level in spleen lymphocytes at various times after infection with REV, MDV or REV+MDV and compare them with those in uninfected age-matched controls, so as to delineate the role of IFN- $\gamma$ in the mechanism of REV- and MDVinduced immunosuppression.

Chickens: Specific pathogen-free (SPF) White Leghorn

* Correspondence to: Zhao, H.-K., College of Veterinry Medicine, Shandong Agricultural University, 61 Daizong Street, Taian, Shandong, 271018, China. chickens (SPAFS, Ji'nan) were maintained in a filtered air, positive pressure house.

Viruses and inoculation of chickens: At 5 days of age, chickens were randomly selected and divided into 4 groups. REV-infected Chickens were inoculated intra-abdominally (i.a.) with $10^{4}$ tissue culture infective doses $50 \%\left(\mathrm{TCID}_{50}\right)$ of the REV-SNV strain [8] (infectious clone of avian the REVSNV strain). MDV-infected chickens were inoculated i.a. with 1,000 plaque-forming-units (PFU) of the serotype 1 strain RB1B. For co-infection with REV and MDV, chickens were inoculated i.a. with REV and MDV as described above. Another group of uninfected chickens was used for the control. At 3, 7, 15, 28 and 50 days post-infection (dpi), 6 chickens from each group were killed, and spleens were collected aseptically.

Preparation of spleen lymphocytes: Spleen lymphocytes were prepared referred to reference [1]. More than $95 \%$ of cells were determined viable by trypan blue dye exclusion. Cells $\left(3 \times 10^{6} / \mathrm{m} l\right)$ were seeded into the 24-well plates and incubated at $41^{\circ} \mathrm{C}$ in $5 \% \mathrm{CO}_{2}$. Cell supernatants were harvested at $60 \mathrm{hr}$. The concentrations of IFN- $\gamma$ were measured as described below.

Chicken IFN- $\gamma$ ELISA: Ninety-six-well flat-bottom microtiter plates were coated with $100 \mu \mathrm{l} /$ well of a solution containing $2 \mu \mathrm{g} / \mathrm{m} l$ coating antibody (anti-chicken IFN- $\gamma$ $\mathrm{mAb}$, Biosource) in phosphate buffered saline (PBS, $\mathrm{pH}$ 7.2) for $18 \mathrm{hr}$ at $4^{\circ} \mathrm{C}$, aspirated, then blocked for $2 \mathrm{hr}$ at room temperature by adding $300 \mu \mathrm{l} /$ well PBS-1\%BSA. After three times washes with PBS containing $0.2 \%$ Tween-20 (PBS-T), diluted standards (natural chicken IFN- $\gamma$, Biosource), controls and samples were added at $100 \mu \mathrm{l} /$ well followed immediately by addition of $50 \mu \mathrm{l} /$ well of biotinylated antibody (mouse anti-chicken IFN- $\gamma \mathrm{mAb}, 0.1 \mu \mathrm{g} / \mathrm{ml}$, Biosource) in PBS-T-1\%BSA. Plates were incubated for $2 \mathrm{hr}$ at 
room temperature with continual shaking (700 rpm), wahed three times and incubated with HRP-labeled Streptavidin $(1: 2,500$, Biosource) for $30 \mathrm{~min}$. After wahses, $100 \mathrm{ml} /$ well of the Chromogen tetramethylbenzidine (Sigma) was added and incubated for $30 \mathrm{~min}$. Substrate reaction was stopped with $2 \mathrm{~N} \mathrm{H}_{2} \mathrm{SO}_{4}$, and the optical density (OD) values were measured at $450 \mathrm{~nm}$ within $30 \mathrm{~min}$ of adding stop solution. Construct a standard curve by plotting each standard OD (ordinate) vs. the standard concentration (abscissa). Determine the concentration of each unknown sample from the standard curve.

Statistical analysis: The statistical differences between groups were determined by the Student's $t$-test using Microsoft Excel, and significant differences were evaluated at a probability levels of $<0.05$.

Quantitation of IFN- $\gamma$ by Ag capture ELISA: To determine if the Ag capture ELISA was capable to quantifying IFN- $\gamma$ in spleen lymphocytes culture supernatant, as a preexperiment, 6 chickens from the group co-infected with REV and MDV were killed for spleens at $7 \mathrm{dpi}$, and culture supernant were collected at different times. Figure 1 shows the IFN- $\gamma$ level determination in the culture supernant of spleen lymphocytes from chickens co-infected with REV and MDV using IFN- $\gamma$ ELISA. The IFN- $\gamma$ levels in spleen lymphocytes culture supernatant were highest at $60 \mathrm{hr}$ postincubation, the value is $74.36 \pm 26.95 \mathrm{pg} / \mathrm{ml}$, and then decreased gradually in a time-dependent manner. The viabilities of the cells were not significantly different within 72 hr.

Effects of different viruses infection on IFN- $\gamma$ production in chicken spleen lymphocytes culture supernatant: As shown in Fig. 2, IFN- $\gamma$ of spleen lymphocytes from chickens infected with REV was low at 3 dpi, but values were not significantly different compared to controls $(18.47 \pm 9.78 \mathrm{pg} /$ $\mathrm{m} l$ vs. $22.08 \pm 0.23 \mathrm{pg} / \mathrm{ml}, \mathrm{n}=6, \mathrm{P}>0.05)$. At $7 \mathrm{dpi}, \mathrm{REV}$ alone caused a 5-fold increase $(109.81 \pm 49.13 \mathrm{pg} / \mathrm{ml}$ vs. $20.96 \pm 1.23 \mathrm{pg} / \mathrm{m} l \mathrm{n}=6, \mathrm{P}>0.01)$, the IFN- $\gamma$ level paked, and then gradually decreased. At $28 \mathrm{dpi}$, REV alone caused a 3fold increase $(61.02 \pm 18.86 \mathrm{pg} / \mathrm{m} l$ vs. $23.22 \pm 3.73 \mathrm{pg} / \mathrm{m} l$, $\mathrm{n}=6, \mathrm{P}<0.01)$, at $50 \mathrm{dpi}$, IFN- $\gamma$ levels were not significantly different compared to controls $(28.13 \pm 5.05 \mathrm{pg} / \mathrm{m} l$ vs. 21.09 $\pm 4.95 \mathrm{pg} / \mathrm{ml}, \mathrm{n}=6, \mathrm{P}>0.05$ ).

In chickens infected with MDV, IFN- $\gamma$ of spleen lymphocytes was below the limits of detection $(<10 \mathrm{pg} / \mathrm{m} l)$ at $3 \mathrm{dpi}$, the values were highly significantly different compared to controls $(8.24 \pm 1.67 \mathrm{pg} / \mathrm{m} l$ vs. $22.08 \pm 0.23 \mathrm{pg} / \mathrm{m} l, \mathrm{n}=6$, $\mathrm{P}<0.01)$. At $7 \mathrm{dpi}$, the IFN- $\gamma$ levels in spleen lymphocytes were similar to those in control $(18.21 \pm 10.43 \mathrm{pg} / \mathrm{m} l \mathrm{vs}$. $20.96 \pm 1.23 \mathrm{pg} / \mathrm{ml}, \mathrm{n}=6, \mathrm{P}>0.05)$. At $15 \mathrm{dpi}$, the levels of IFN- $\gamma$ decreased, the values were significantly different compared to controls $(15.09 \pm 6.66 \mathrm{pg} / \mathrm{m} l$ vs. $21.94 \pm 1.63$ $p \mathrm{~g} / \mathrm{m} l, \mathrm{n}=6, \mathrm{P}<0.05)$. Then IFN- $\gamma$ slightly increased. Although, at $50 \mathrm{dpi}$, IFN- $\gamma$ ELISA demonstrated an increase in FIN- $\gamma$ levels, but showed no significant differences with the controls $(18.44 \pm 5.07 \mathrm{pg} / \mathrm{ml}$ vs. $21.09 \pm 4.95 \mathrm{pg} / \mathrm{ml}$, $\mathrm{n}=6, \mathrm{P}>0.05)$.

IFN- $\gamma$ of spleen lymphocytes from chickens infected with

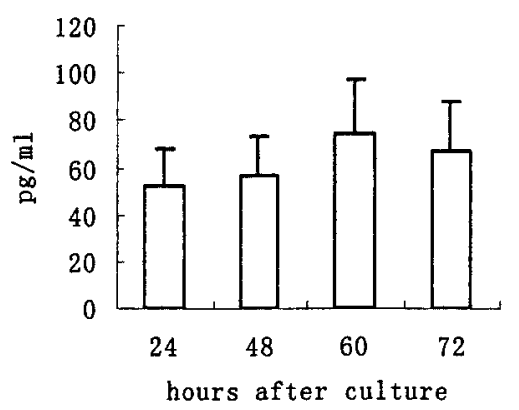

Fig. 1. The optimum time for measurement of IFN- $\gamma$ in chickens co-infected with REV and MDV Chickens were co-infected with REV and MDV at 5 days of age and 6 chickens were killed for spleen, culture supernatants were collected at 24, 48, 60, 72 $\mathrm{hr}$ and subjected to Ag capture ELISA. The results are shown as means \pm SD. The IFN- $\gamma$ levels in spleen lymphocytes were highest at $60 \mathrm{hr}$ post-incubation.

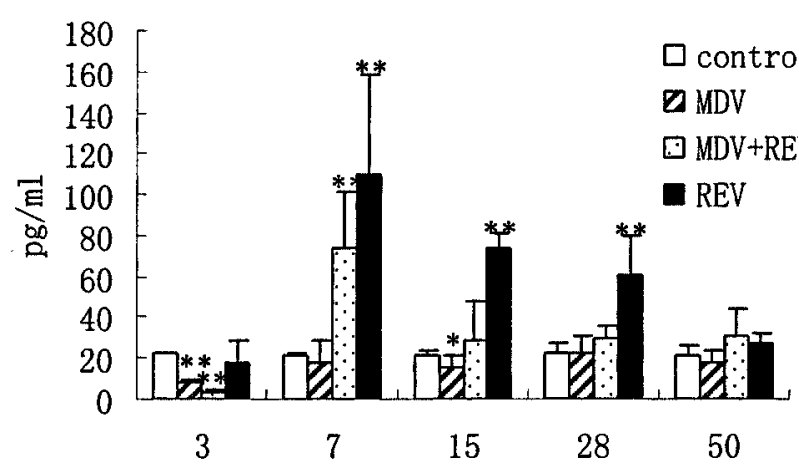

Fig. 2. Changes in IFN- $\gamma$ levels in REV- and MDV- or REV+MDV-infected chickens 6 chickens per group were killed for spleen, culture supernatants were collected at $60 \mathrm{hr}$ and subjected to Ag capture ELISA. The results are shown as means \pm SD. $* \mathrm{P}<0.05, * * \mathrm{P}<0.01$.

REV+MDV was below the limits of detection $(<10 \mathrm{pg} / \mathrm{ml})$ at $3 \mathrm{dpi}$, the values were highly significantly different compared to controls $(3.52 \pm 1.82 \mathrm{pg} / \mathrm{m} l$ vs. $22.08 \pm 0.23 \mathrm{pg} / \mathrm{ml}$, $\mathrm{n}=6, \mathrm{P}<0.01)$. For chickens co-infected with REV and MDV, IFN- $\gamma$ ELISA demonstrated a 3-fold increase in IFN$\gamma$ levels at $7 \mathrm{dpi}(74.36 \pm 26.95 \mathrm{pg} / \mathrm{m} l$ vs. $20.96 \pm 1.23 \mathrm{pg} / \mathrm{ml}$, $\mathrm{n}=6, \mathrm{P}<0.01)$. Especially the concentration of IFN- $\gamma$ in spleen lymphocytes from one of the chickens infected with $\mathrm{REV}+\mathrm{MDV}$ was $800.83 \mathrm{pg} / \mathrm{ml}$, nearly 40 -fold compared to the age-matched controls $(\mathrm{P}<0.001)$. Tumors in the spleen were observed in the case. From 15 dpi to 50 dpi, IFN- $\gamma$ levels of culture supernatants gradually decreased, IFN- $\gamma$ were not significantly different compared to controls $(\mathrm{P}>0.05)$.

Effects of different viruses infection on IFN- $\gamma$ production in chicken spleen lymphocytes culture supernatant incubated with ConA: To determine the effects of different viruses and ConA on IFN- $\gamma$ production, $30 \mu \mathrm{g} / \mathrm{m} l$ ConA was added into the culture supernatant of spleen from virusinfected chickens. As shown in Fig. 3, there were no significant differences in production of IFN- $\gamma$ compared with the values for the culture supernatant without ConA of spleen 


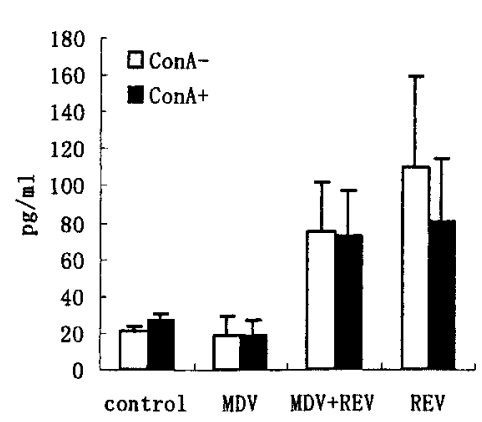

Fig. 3. Chnages in IFN- $\gamma$ levels in REV- and MDV- or REV+MDV-infected chickens spleen lymphocytes incubated with ConA Chickens were infected with REV and MDV or REV+MDV at 5 days of age and 6 chickens per group were killed for spleen. Spleen lymphocytes were seeded into the 24well plates and incubated with or without ConA $(30 \mu \mathrm{g} / \mathrm{m} l)$ and culture supernatants were collected at $60 \mathrm{hr}$ post-stimulation and subjected to Ag capture ELISA. The results are shown as means $\pm \mathrm{SD}$.

from REV- and/or MDV-infected chickens $(\mathrm{P}>0.05)$. For the control, no marked increase was observed in the IFN- $\gamma$ level for ConA group, and no statistical significance was shown in Fig. 3.

This is the first report of IFN- $\gamma$ production in SPF chickens infected with REV and MDV measured by Ag capture ELISA. First, Chickens were infected with REV and MDV or REV+MDV at 5 days of age and examined from 3 to 50 dpi. In REV+MDV co-infection chickens, IFN- $\gamma$ ELISA demonstrated a 3 -fold increase in IFN- $\gamma$ levels at 7 dpi. Increased levels of IFN- $\gamma$, ranging from 3- to 5-fold, were evident in chickens infected with REV between 7 and 28 dpi. IFN- $\gamma$ levels significantly decreased in MDV infection at $3 \mathrm{dpi}$ and $15 \mathrm{dpi}$. Second, for REV- and/or MDVinfected chickens, the IFN- $\gamma$ levels decreased slightly for adding ConA group. These results have important consequences for the poultry industry because REV is likely to be a much more important pathogen than was previously believed. Protective immunity induced by vaccination or natural infection with viruses requires a strong cell-mediated component for protection or recovery from infection as has been documented for MDV [5]. Increased incidence of MD in broilers has been linked with an increased incidence of REV in chickens. This suggests that REV can have an impact on MD incidence. Further, MDV and REV could be examined in the blood from 7 to $45 \mathrm{dpi}$, and thymus and bursa of Fabricius atrophied, immune index of thymus and brusa of Fabricius were markedly significantly compared with the age-matched control (published in another article).

This work has shown differential IFN- $\gamma$ concentrations in spleen lymphocytes of chickens following REV infection. The IFN- $\gamma$ levels in chickens infected with REV were significantly different compared to controls. Markowski-Grimsured and Schat [11] demonstrated that infection with REV (REV-CS strain) alone resulted in 10-fold increase in IFN- $\gamma$ mRNA levels in 9- to 10- or 30-day-old birds. All these indicated that REV was a strong inducer of IFN- $\gamma$. REV- transformed cell lines are strong producers of IFN- $\gamma$, but vrel, capable of up-regualting genes, was expressed in these cell lines. However, the SNV strain of REV lacks the v-rel gene, the CS strain also lacks this gene. Therefore, there must be exist another mechanism responsible for the strong induction of IFN- $\gamma$. Thus, it is now necessary to perform further examination.

For IFN- $\gamma$ production in MDV-infected chickens, most of the studies have been performed by RT-PCR. Xing and Schat [13] showed that IFN- $\gamma$ transcription was up-regulated at $3 \mathrm{dpi}$ until the termination of the experiment at $15 \mathrm{dpi}$ in MDV-infected chickens at 1 day of age. Kaiser et al. [9] found that IFN- $\gamma$ mRNA was expressed by splenocytes from all infected birds between 3 and $10 \mathrm{dpi}$, associated with increasing MDV loads. But the extents of IFN- $\gamma$ mRNA upregulation were similar between the resistant and susceptible inbred lines. Quere et al. [12] found that MDV infection did not change the circulating level of IFN- $\gamma$ mRNA 1 and $7 \mathrm{dpi}$, but they increased IFN- $\alpha$ mRNA levels slightly in genetically susceptible chickens. Further, MDV was able to block the response to inactivated Newcastle disease virus, a potent inducer of IFN, in chickens. The inhibiting effect on transcription was present for IFN- $\gamma$ and IFN- $\alpha$ in the blood as soon as $1 \mathrm{dpi}$ in susceptible chickens. In this study, MDV alone caused a significant decrease at $3 \mathrm{dpi}$ and $15 \mathrm{dpi}$. This study and the study described above could be because different techniques, virus strain, the chickens' age and/or genetics were used to evaluate the effects of MDV infection on IFN- $\gamma$ production. Large increase in pro-inflammatory such as IL- $1 \beta$, IL- 6 , and IL- 8 were seen in the brains of RK1 (RK-1 strain of MDV)-infected chickens [7]. A further study will be made to determine which kind of the cytokines or cytokine network plays a pivotal role in the mechanism of MDV-induced immunosuppression.

ACKNOWLEDGEMENT. The authors thank Dr. Jing-He TAN and Dr. Kaiser P for their kindness assistance. This work was supported by a grant (key program, No. 30330450) from national natural science found.

\section{REFERENCES}

1. Beal, R. K., Powers, C., Wigley, P., Barrow, P. A., Kaiser, P. and Smith, A. L. 2005. Infect. Immun. 73: 7509-7516.

2. Buscaglia, C. and Calnek, B. W. 1988. J. Gen. Virol. 69: 28092818.

3. Davidson, I. and Borenshtain, R. 1999. Acta Virol. 43: 136142.

4. Davidson, I. and Borenshtain, R. 2001. Avian Dis. 45: 102121.

5. Gimeno, I. M., Witter, R. L., Hunt, H. D., Reddy, S. M. and Reed, W. M. 2004. Avian Pathol. 33: 59-68.

6. Islam, A. F., Wong, C. W. and Walkden-Brown, S. W., Colditz, I. G., Arzey, K. E. and Groves, P. J. 2002. Avian Pathol. 31: 449-461.

7. Jarosinski, K. W., Njaa, B. L., O'connell, P. H. and Schat, K. A. 2005. Viral Immunol. 18: 148-161.

8. Ji, R., Cui, Z. Z., Wang X. L. and Sun, S. H. 2005. Chinese Journal of Virology 21: 448-455. 
9. Kaiser, P., Undrwood, G. and Davison, F. 2003. J. Virol. 77: 762-768.

10. Karaca, G., Anobile, J., Downs, D., Burnside, J. and Schmidt, C. J. 2004. Virology. 318: 102-111.

11. Markowski-Grimsrud, C. J. and Schat, K. A. 2003. Immunology 109: 283-294.

12. Quere, P., Rivas, C., Ester, K., Novak, R. and Ragland, W. L.
2005. Arch Virol. 150: 507-519.

13. Xing, Z. and Schat, K. A. 2000. Immunology 100: 70-76.

14. Yukio, Y., Aiko, O., Hiroki, S., Yukio, C. and Takashi, I. 2003. J. Vet. Med. Sci. 65: 1355-1359.

15. Yunis, R., Jarosinski, K. W. and Schat, K. A. 2004. Virology 328: $142-150$ 